\title{
Influence of exercise duration on cardiorespiratory responses, energy cost and tissue oxygenation within a 6 hour treadmill run
}

\author{
Hugo A Kerhervé erresp., ${ }^{1}$, Scott McLean ${ }^{1}$, Karen Birkenhead $^{1}{ }^{\text {, }}$, David Parr ${ }^{1}$, Colin Solomon $^{1}$ \\ ${ }^{1}$ School of Health and Sport Sciences, University of the Sunshine Coast, Sippy Downs, QLD, Australia \\ Corresponding Author: Hugo A Kerhervé \\ Email address: hkerherv@usc.edu.au
}

Purpose: The physiological mechanisms for alterations in oxygen utilization (VO2) and the energy cost of running $\left(\mathrm{C}_{\mathrm{r}}\right)$ during prolonged running are not completely understood, and could be linked with alterations in muscle and cerebral tissue oxygenation. Methods: Eight trained ultramarathon runners ( 3 women; mean \pm SD; age $37 \pm 7 \mathrm{yr}$; maximum VO2 $60 \pm 15 \mathrm{~mL} \cdot \mathrm{min}^{-1} \cdot \mathrm{kg}^{-1}$ ) completed a $6 \mathrm{hr}$ treadmill run (6TR), which consisted of four modules, including periods of moderate ( $3 \mathrm{~min}$ at $10 \mathrm{~km} \cdot \mathrm{h}^{-1}, 10-\mathrm{CR}$ ) and heavy exercise intensities ( $6 \mathrm{~min}$ at $70 \%$ of maximum VO2, HILL), separated by three, 100 min periods of self-paced running (SP). We measured VO2, minute ventilation (VE), ventilatory efficiency (VE:VO2), respiratory exchange ratio (RER), $C_{r}$, muscle and cerebral tissue saturation index (TSI) during the modules, and heart rate (HR) and perceived exertion (RPE) during the modules and SP. Results: Participants ran $58.3 \pm 10.5$ km during 6TR. Speed decreased and HR and RPE increased during SP. Across the modules, HR and VO2 increased (10-CR), and RER decreased (10-CR and HILL). There were no significant changes in VE, VE:VO2, $\mathrm{C}_{r}$, TSI and RPE across the modules. Conclusions: In the context of positive pacing (decreasing speed), increased cardiac drift and perceived exertion over the 6TR, we observed increased RER and increased HR at moderate and heavy exercise intensity, increased VO2 at moderate intensity, and no effect of exercise duration on ventilatory efficiency, energy cost of running and tissue oxygenation. 
1 Title

2 Influence of exercise duration on cardiorespiratory responses, energy cost and tissue oxygenation

3 within a 6 hour treadmill run

\section{Running head}

$5 \quad$ Physiology of long duration running

\section{Authors}

7 Hugo A. Kerhervé, Scott McLean, Karen Birkenhead, David Parr, Colin Solomon

\section{Affiliation}

9 School of Health and Sport Sciences, Faculty of Science, Health, Education and Engineering,

10 University of the Sunshine Coast, Australia

\section{Address for correspondence}

12 Hugo Kerhervé, School of Health and Sport Science, University of the Sunshine Coast, 90 Sippy

13 Downs Drive, Sippy Downs, QLD 4556, Australia

14 e-mail: hkerherv@usc.edu.au

15 ORCID: orcid.org/0000-0002-3163-7456

16

Abstract word count:

$237 \mathrm{w}$

18 Text-only word count:

$4512 \mathrm{~W}$

19 Number of tables and figures:

3 tables, 3 figures

20

Ethics Approval:

Approved by the research ethics committee of the University of the Sunshine (Coast S/12/432) 


\section{Abstract}

24 Purpose: The physiological mechanisms for alterations in oxygen utilization $\left(\mathrm{V}_{2}\right)$ and the energy

25 cost of running $\left(\mathrm{C}_{\mathrm{r}}\right)$ during prolonged running are not completely understood, and could be linked with alterations in muscle and cerebral tissue oxygenation. Methods: Eight trained ultramarathon runners ( 3 women; mean $\pm \mathrm{SD}$; age $37 \pm 7 \mathrm{yr}$; maximum $\dot{\mathrm{VO}} \mathrm{O}_{2} 60 \pm 15 \mathrm{~mL} \cdot \mathrm{kg}^{-1} \cdot \mathrm{min}^{-1}$ ) completed a $6 \mathrm{hr}$ treadmill run (6TR), which consisted of four modules, including periods of moderate ( 3 min at $10 \mathrm{~km} \cdot \mathrm{h}^{-1}, 10-\mathrm{CR}$ ) and heavy exercise intensities (6 min at $70 \%$ of maximum $\dot{\mathrm{V}} \mathrm{O}_{2}, \mathrm{HILL}$ ), separated by three, 100 min periods of self-paced running (SP). We measured $\dot{\mathrm{V}}_{2}$, minute ventilation $\left(\dot{\mathrm{V}}_{\mathrm{E}}\right)$, ventilatory efficiency $\left(\dot{\mathrm{V}}_{\mathrm{E}}: \dot{\mathrm{V}}_{2}\right)$, respiratory exchange ratio $(\mathrm{RER}), \mathrm{C}_{\mathrm{r}}$, muscle and cerebral tissue saturation index (TSI) during the modules, and heart rate (HR) and perceived exertion (RPE) during the modules and SP. Results: Participants ran $58.3 \pm 10.5 \mathrm{~km}$ during 6TR. Speed decreased and HR and RPE increased during SP. Across the modules, HR and $\dot{\mathrm{V}} \mathrm{O}_{2}$ increased (10-CR), and RER decreased (10-CR and HILL). There were no significant changes in $\dot{\mathrm{V}}_{\mathrm{E}}, \dot{\mathrm{V}}_{\mathrm{E}}: \dot{\mathrm{V}}$ $\mathrm{O}_{2}, \mathrm{C}_{\mathrm{r}}$, TSI and RPE across the modules. Conclusions: In the context of positive pacing (decreasing speed), increased cardiac drift and perceived exertion over the 6TR, we observed increased RER and increased $\mathrm{HR}$ at moderate and heavy exercise intensity, increased $\dot{\mathrm{V}} \mathrm{O}_{2}$ at moderate intensity, and no effect of exercise duration on ventilatory efficiency, energy cost of running and tissue oxygenation. 


\section{Introduction}

43 Paragraph \#1. Maximal oxygen utilization $\left(\dot{\mathrm{V}} \mathrm{O}_{2 \mathrm{MAX}}\right)$, the fractional rate of $\dot{\mathrm{V}} \mathrm{O}_{2 \mathrm{MAX}}\left(\% \dot{\mathrm{V}} \mathrm{O}_{2 \mathrm{MAX}}\right)$ and the energy cost of running $\left(\mathrm{C}_{\mathrm{r}}\right)$, i.e. the submaximal metabolic demand per unit distance, are primary predictors of performance in marathon and ultramarathon running (di Prampero et al. 1986; Lazzer et al. 2012), and may be affected by prolonged duration exercise. Increased $\dot{\mathrm{V}} \mathrm{O}_{2}$ and $\mathrm{C}_{\mathrm{r}}$ were measured after one hour of running at $\sim 80 \% \dot{\mathrm{V}} \mathrm{O}_{2 \mathrm{MAX}}$ (Hunter \& Smith 2007), after $90 \mathrm{~min}$ at $65 \%$ and $80 \% \dot{\mathrm{V}} \mathrm{O}_{2 \mathrm{MAX}}(\mathrm{Xu} \&$ Montgomery 1995), and after self-paced marathon events (Hausswirth et al. 1996; Kyröläinen et al. 2000; Nicol et al. 1991). It has been suggested that increases in $\mathrm{C}_{\mathrm{r}}$ correlates positively with distance covered (Brueckner et al. 1991; Lazzer et al. 2012). However, for longer durations of running, this relationship was not observed: $\dot{V} O_{2}$ and $C_{r}$ increased only during the first $8 \mathrm{~h}$ of a $24-\mathrm{h}$ treadmill run performed at $\sim 40 \%$ of the velocity associated with $\dot{\mathrm{V}} \mathrm{O}_{2 \mathrm{MAX}}$ (Gimenez et al. 2013), and there was no change in $\mathrm{C}_{\mathrm{r}}$ despite increased energy cost of cycling after a $65 \mathrm{~km}$ trail ultramarathons, (Millet et al. 2000). Also following a 65 $\mathrm{km}$ mountain ultramarathon, $\mathrm{C}_{\mathrm{r}}$ did not change and $\dot{\mathrm{V}}_{2}$ increased when tested on level ground (10 $\left.\mathrm{km} \cdot \mathrm{h}^{-1}\right), \mathrm{C}_{\mathrm{r}}$ and $\dot{\mathrm{V}} \mathrm{O}_{2}$ did not change when tested on uphill gradients $\left(10 \mathrm{~km} \cdot \mathrm{h}^{-1}, 5 \%\right.$ grade $)$, but $\mathrm{C}_{\mathrm{r}}$ and $\dot{\mathrm{V}} \mathrm{O}_{2}$ increased on a downhill gradient $\left(10 \mathrm{~km} \cdot \mathrm{h}^{-1},-5 \%\right.$ grade) (Vernillo et al. 2015). The situation changed again following a $330 \mathrm{~km}$ mountain ultramarathon, where $\mathrm{C}_{\mathrm{r}}\left(\right.$ at 6 and $8 \mathrm{~km} \cdot \mathrm{h}^{-}$ $\left.{ }^{1}\right)$ and the energy cost of walking (at $5 \mathrm{~km} \cdot \mathrm{h}^{-1}$ ) improved (decreased) on an uphill gradient (15\%) (Vernillo et al. 2016b; Vernillo et al. 2014).

Paragraph \#2. The physiological basis for increased $\dot{\mathrm{V}} \mathrm{O}_{2}$ and $\mathrm{C}_{\mathrm{r}}$ could be related to decreases in cardiorespiratory efficiency, such as increased heart rate (HR) (Kyröläinen et al. 2000), increased pulmonary ventilation $\left(\dot{\mathrm{V}}_{\mathrm{E}}\right)$ and decreased pulmonary efficiency $\left(\dot{\mathrm{V}}_{\mathrm{E}}: \dot{\mathrm{V}} \mathrm{O}_{2}\right)$ (Millet et al. 2000; Vernillo et al. 2016b; Vernillo et al. 2014). The different outcomes in $\dot{\mathrm{V}} \mathrm{O}_{2}$ and $\mathrm{C}_{\mathrm{r}}$ responses observed following ultramarathons could be attributed to decreased respiratory exchange ratio (RER) (Gimenez et al. 2013; Kyröläinen et al. 2000; Vernillo et al. 2016b; Vernillo et al. 2015; Vernillo et al. 2014). However, other tissue-specific adaptations could also contribute to variations in $\mathrm{VO}_{2}$ and $\mathrm{C}_{\mathrm{r}}$ during prolonged running, such as increased neural input and impairments in the structural integrity of the musculoskeletal system (Kyröläinen et al. 2000; Vernillo et al. 2015). 
For instance, tissue oxygenation in the vastus lateralis muscle (VL) measured using near-infrared spectroscopy (NIRS) decreased following a $330 \mathrm{~km}$ running ultramarathon, without changes in $\dot{V}$ $\mathrm{O}_{2}$ (Vernillo et al. 2016a), though the specific effects of the structural disruption of muscle tissue and of exercise duration on tissue oxygenation were not tested. Contrasting with these results, VL oxygenation increased following a 45-min, high intensity intermittent running exercise (Sear et al. 2010), VL muscle oxygen utilization and muscle blood flow increased following $\sim 95$ min of trail running (Vercruyssen et al. 2012), and VL oxygenation did not change during 4-h of cycling including three, 80 min exercise periods at $45 \%$ of maximal power output (Rupp et al. 2013). Therefore, the specific effects of exercise duration on tissue oxygenation are not known.

Paragraph \#3. Oxygenation of the prefrontal cortex (PFC) could also be directly involved in exercise regulation by integrating signals of homeostatic disturbances, and decreases in PFC oxygenation could reflect a decreased exercise tolerance (Robertson \& Marino 2016). Although cerebral tissue oxygenation did not change as a function of duration during 4-h of cycling (Rupp et al. 2013), exercise intensity may have been too low for comparisons with existing studies in prolonged running except for those conducted during $24 \mathrm{~h}$ or $300 \mathrm{~km}$ ultramarathons, and no research has currently described PFC oxygenation during prolonged running. Indirect estimations of neural input can also be gained using ratings of perceived exertion (RPE) (deMorree et al. 2012), which have been described to correlate with HR and ventilatory rate (Hampson et al. 2001; Mihevic 1981; Nicolò et al. 2015; Tucker \& Noakes 2009), but not $\dot{\mathrm{V}}_{\mathrm{E}}$ or $\dot{\mathrm{V}}_{2}$ (Hampson et al. 2001; Nicolò et al. 2015).

Paragraph \#4. Therefore, the aim of this study was to determine muscle and cerebral tissue oxygenation, cardiorespiratory $\left(\dot{\mathrm{V}}_{2}, \dot{\mathrm{V}}_{\mathrm{E}}, \dot{\mathrm{V}}_{\mathrm{E}}: \dot{\mathrm{V}}_{2}\right.$, respiratory exchange ratio [RER], HR), $\mathrm{C}_{\mathrm{r}}$ and RPE within a 6 hour running exercise on a treadmill (6TR). The duration of exercise was selected for comparison with previous literature (Millet et al. 2000; Vernillo et al. 2015), including a study having measured decreased PFC activity (Wollseiffen et al. 2016), and to correspond to the acute phase of alterations in $\dot{\mathrm{VO}}_{2}$ and $\mathrm{C}_{\mathrm{r}}$ observed in a previous study (Gimenez et al. 2013). To establish the specific effect of exercise duration, we aimed to measure the selected parameters at a moderate intensity (Gaesser \& Poole 1996) corresponding to the expected average speed of a group of trained ultramarathon runners, and at a heavy exercise intensity (Gaesser \& Poole 1996) 
99

100

101

102

103

104

105

106

107

108

109

110

111

112

113

114

115

116

117

118

119

120

121

122

123

124

125

minimizing the contribution of eccentric contractions to mechanical work, i.e. uphill (Minetti et al. 1994). Based on the specific literature, we hypothesized that 1) cardiorespiratory and RPE responses would increase throughout the $6 \mathrm{TR} ; 2$ ) tissue oxygenation would decrease as a function of duration only in PFC at the moderate intensity, and decrease in PFC and muscle tissues at heavy intensity ; and 3) $\mathrm{C}_{\mathrm{r}}$ responses would remain unchanged throughout the 6TR.

\section{Methods}

\section{Ethical statement and participants}

Paragraph \#5. This study was approved by the Human Research Ethics Committee of the University of the Sunshine Coast (Approval Number: S/12/432). Participants were informed of the experiment protocol and associated risks, and provided written informed consent for participation. The participant group consisted of eight healthy and trained ultramarathon runners (3 women and 5 men: mean $\pm \mathrm{SD}$; age $37.4 \pm 7.4$; yr; height: $176 \pm 5.3 \mathrm{~cm}$; weight: $70.5 \pm 8.9 \mathrm{~kg}$; $\mathrm{VO}_{2 \mathrm{MAX}}: 60.1$ $\left.\pm 14.5 \mathrm{~mL} \cdot \mathrm{kg}^{-1} \cdot \mathrm{min}^{-1}\right)$.

\section{Study procedures}

Design

Paragraph \#6. The participants attended the laboratory for two separate sessions within a 15-day period. At the first session, participants completed screening procedures (medical history questionnaire, pulmonary function, anthropometric characteristics) and an incremental maximal running test on a treadmill (T200, Cosmed, Rome, Italy) to volitional exhaustion, consisting of 3 $\min$ at $6 \mathrm{~km} \cdot \mathrm{h}^{-1}$ and $0 \%$ grade, then 1 min stages incremented by $2.5 \%$ grade each min at $6 \mathrm{~km} \cdot \mathrm{h}^{-}$ ${ }^{1}$ up to a maximum of $10 \%$ grade, then 3 min stages incremented by $1 \mathrm{~km} \cdot \mathrm{h}^{-1}$. For the running test, $\dot{\mathrm{VO}}_{2}$ was measured continuously using a two-way, non-rebreathing valve (series 2700, HansRudolph, Kansas City, USA) and an automated open-circuit spirometry respiratory gas analysis system (True One 2400, Parvo Medics, Sandy UT). We monitored HR using a chest strap and watch (RS800, Polar Electro, Kempele, Finland; Ambit, Suunto Oy, Vantaa, Finland) recording at $1 \mathrm{~Hz}$. The incremental maximal running test was used to determine maximum heart rate ( $\left.\mathrm{HR}_{\mathrm{MAX}}\right)$, $\dot{\mathrm{V}} \mathrm{O}_{2 \mathrm{MAX}}$, and the velocity eliciting $70 \%$ of $\dot{\mathrm{V}} \mathrm{O}_{2 \mathrm{MAX}}\left(70 \% \mathrm{v} \dot{\mathrm{V}} \mathrm{O}_{2 \mathrm{MAX}}\right)$ at $10 \%$ grade. 
126 Paragraph \#7. At the second session, participants completed the 6TR with the aim to run the

127

128

129

130

131

132

133

134

135

136

137

138

139

140

141

142

143

144

145

146

147

148

149

150

151

152 maximum distance possible, which included four repetitions of a 15 min testing module at 0,105 , 225 and $345 \mathrm{~min}$, each separated by $100 \mathrm{~min}$ of self-paced running (SP) (Figure 1). Each module consisted of $3 \mathrm{~min}$ at a self-selected speed, 3 min of moderate intensity running at a fixed speed of $10 \mathrm{~km} \cdot \mathrm{h}^{-1}(10-\mathrm{CR}), 6 \mathrm{~min}$ of high intensity running at the speed eliciting $70 \% \mathrm{vV} \mathrm{O}_{2 \mathrm{MAX}}$ at a $10 \%$ grade (HILL), and $3 \mathrm{~min}$ at a self-selected speed. For HILL, the participants had the option to decrease the speed if they perceived they would be unable to complete the condition and/or complete the 6TR, and were instructed to select the highest possible speed for the condition. This modification had to happen during the first two minutes of HILL to ensure data was collected at steady state. One participant completed the modules at 0,110, 235 and $345 \mathrm{~min}$, but the difference in timing was considered to have no effect on the combined results. During the SP periods participants could vary their speed, walk or stop ad libitum (time was not stopped for toilet breaks, and the distance to the toilets was added to the total), and were provided with performance feedback if requested. Participants were instructed to follow their normal nutrition and hydration routine. The actual running duration was $6 \mathrm{~h}$, and the mean total time stopped (to attach and remove the testing equipment for the modules) was $18 \pm 1$ min (Figure 1).

*** insert Figure 1 about here ***

Performance and relative exercise intensity

Paragraph \#8. Running time, speed, distance, gradient and HR were monitored continuously throughout the 6TR (the treadmill was calibrated for speed and gradient using standard procedures). The ratio of heart rate and speed was used to calculate the Physiological Cost Index $\left(\mathrm{PCI}=\mathrm{HR} / \mathrm{V}\right.$, where HR is the average heart rate in beat $\cdot \mathrm{min}^{-1}$, and $\mathrm{V}$ is the running speed in $\mathrm{m} \cdot \mathrm{min}^{-1}$; PCI is expressed in beat $\cdot \mathrm{m}^{-1}$ ). This index is a better indicator of cardiovascular drift and metabolic efficiency than HR only, as it includes the effect of speed on physiological load (Gimenez et al. 2013). Speed, \%HR $\mathrm{MAX}_{\mathrm{X}}$ and PCI were reported for the three SP periods (average of SP1, SP2, SP3) and during the modules at steady state (30 s average during the final minute of 10-CR and HILL conditions). 
153

154 Paragraph \#9. The rate of oxygen utilization $\left(\dot{\mathrm{V}}_{2}\right)$, the rate of carbon dioxide production $\left(\dot{\mathrm{V} C \mathrm{CO}_{2}}\right)$,

\section{Gas exchange measurements} minute ventilation $\left(\dot{\mathrm{V}}_{\mathrm{E}}\right)$, ventilatory equivalent $\left(\dot{\mathrm{V}}_{\mathrm{E}}: \dot{\mathrm{V}} \mathrm{O}_{2}\right)$ and the respiratory exchange ratio $(\mathrm{RER}=$ 156 $\dot{\mathrm{V} C \mathrm{CO}_{2}}: \dot{\mathrm{VO}}_{2}$ ) were measured during the modules of the 6TR using the same apparatus as for the first session, which was calibrated shortly before data collection. Temperature, humidity and barometric pressure were monitored throughout the tests, and the system was recalibrated if any changes were observed. Sampling lines were removed and left to dry between modules. Absolute rate $\left(\mathrm{g} \cdot \mathrm{min}^{-1}\right)$ of fat $\left(\mathrm{OX}_{\mathrm{FAT}}\right)$ was calculated based on the assumption that the excretion of urinary nitrogen was negligible using Equation 1 (Frayn 1983):

$$
\text { (eq. 1) } \quad \mathrm{OX}_{\mathrm{FAT}}=1.67 \times \dot{\mathrm{V}} \mathrm{O}_{2}-1.67 \times \dot{\mathrm{V}} \mathrm{CO}_{2}
$$

\section{Energy cost of running}

Paragraph \#10. We calculated the energy cost of running $\left(C_{r}\right.$, in $\left.\mathrm{mL} \cdot \mathrm{kg}^{-1} \cdot \mathrm{m}^{-1}\right)$ as the ratio of net $\dot{V}$ $\mathrm{O}_{2}\left(\mathrm{~mL} \cdot \mathrm{min}^{-1} \cdot \mathrm{kg}^{-1}\right)$ to speed $\left(\mathrm{m} \cdot \mathrm{min}^{-1}\right)$ at steady state $(30 \mathrm{~s}$ average during the last minute of $10-$ $\mathrm{CR}$ and HILL). As $\mathrm{C}_{\mathrm{r}}$ is influenced by the progressive shift to $\beta$-oxidation (RER drift) independent of speed during prolonged exercise such as ultramarathon running (Gimenez et al. 2013), we also calculated the energy cost of running expressed as energy expenditure per unit distance $\left(\mathrm{C}_{\mathrm{r}}^{\mathrm{J}}\right.$, in $\mathrm{J} \cdot \mathrm{kg}^{-1} \cdot \mathrm{m}^{-1}$ ) using an energy equivalent of oxygen ranging from 19.6 to 21.1 depending on RER. An increase in $\mathrm{C}_{\mathrm{r}}^{\mathrm{J}}$ indicates a decrease in running efficiency.

\section{Muscle and cerebral tissue oxygenation}

Paragraph \#11. To assess muscle and cerebral tissue oxygenation, we used 2-wavelength continuous wave NIRS devices (Portamon and Portalite, Artinis Medical Systems BV, Zetten, The Netherlands), measuring changes in deoxyhemoglobin $(\Delta[\mathrm{HHb}])$ and oxyhemoglobin concentrations $\left(\Delta\left[\mathrm{O}_{2} \mathrm{Hb}\right]\right)$ from an arbitrary baseline, and an index of tissue oxygenation $(\mathrm{TSI}=$ $\left.\Delta\left[\mathrm{O}_{2} \mathrm{HB}\right] / \Delta[\mathrm{HHb}] \times 100\right)$. The devices were placed on the VL (at the center of the muscle belly), the lateral head of the Gastrocnemius (Gn, at the center of the muscle belly), and on the prefrontal cortex (PFC, placed above the eyebrow, between the midline of the skull and the temporalis muscle, corresponding to the region between Fp1 and F3 of the modified international EEG 10-20 system, and adjusted individually depending on the largest response during rhythmic and sustained 
181 contractions of the upper and lower limbs). The position of each device was marked on the skin to

182 ensure repeatability of placement. Each device was secured to the skin using adhesive elastic tape, 183 and shielded from ambient light using $20 \times 20 \mathrm{~cm}$ opaque cloth. The NIRS devices were attached 184 and removed immediately before and after each module.

185 Paragraph \#12. Adipose tissue thickness was measured at the two muscle sites using Harpenden 186 calipers (British Indicators Ltd, Burgess Hill, UK) as the thickness influences the NIRS signal (van 187 Beekvelt et al. 2001). As all participants had adipose tissue thicknesses less than half of the inter188 optode distance $(17.5 \mathrm{~mm}$, to ensure an adequate depth of illumination), no participants were 189 excluded (VL: $4.10 \pm 1.99 \mathrm{~mm}$, range 1.6-7.6 mm ; Gn: $4.76 \pm 3.06 \mathrm{~mm}$, range 1.5-8.5 mm). Using the recommendations of the manufacturer, we used a fixed differential pathway factor (DPF) of 4 for all participants for the muscle sites, and an age-dependent DPF was calculated for the PFC (Duncan et al. 1996). The devices collected data at $10 \mathrm{~Hz}$ and the TSI was averaged over $30 \mathrm{~s}$ during the final minute (from 20 to $50 \mathrm{~s}$ of the minute, to exclude potential effects associated with transition phases) of 10-CR and HILL to obtain data representative of the exercise state. Attaching and removing the devices before and after each module was approximately 5 and $1 \mathrm{~min}$, respectively, and was deducted from total running time.

\section{Perceived exertion}

198

199

200

201

202

203

204

205

206

207

208

209

Paragraph \#13. The 6-20 linear Borg scale was used to measure perceived exertion dissociated between general RPE (RPE $\left.E_{\mathrm{GEN}}\right)$, the conscious effort excluding any somatic sensation $\left(\mathrm{RPE}_{\mathrm{CON}}\right)$, and the local (muscular) RPE of the knee extensor muscles excluding any psychological contribution to exertion (RPE $\left.E_{\mathrm{KE}}\right)$. The scale included written descriptors, and participants were familiarized with the scale during the first session. To minimize the confounding effects of the modules, the variables pertaining to self-paced exercise were recorded $33 \mathrm{~min}$ from the start, and 33 min before the end of each SP bout (at $48,82,163,196,278$ and 312 min of total elapsed time during the 6TR) which are referred to as SP1a, SP1b, SP2a, SP2b, SP3a and SP3b, respectively.

\section{Statistical analyses}

Paragraph \#14. Data are reported as mean \pm SD and expressed in percentage change from selfpaced period (SP1) or module (M1). All data were initially tested for normality (Shapiro-Wilk's test). For the data measured during the self-paced periods of running, a one-way, repeated- 
210 measures (RM) ANOVA was used to assess the effect of duration (SP1, SP2, SP3) on speed,

$211 \% \mathrm{HR}_{\text {MAX }}$, PCI, and a two-way RM ANOVA was used to assess the effect of duration (SP1a, SP1b,

$212 \mathrm{SP} 2 \mathrm{a}, \mathrm{SP} 2 \mathrm{~b}, \mathrm{SP} 3 \mathrm{a}, \mathrm{SP} 3 \mathrm{~b})$, category $\left(\mathrm{RPE}_{\mathrm{GEN}}, \mathrm{RPE}_{\mathrm{CON}}, \mathrm{RPE}_{\mathrm{KE}}\right)$ and the interaction (duration $\times$

213 category) in RPE variables. For the variables collected during the modules, a one-way, RM

214 ANOVA was used to assess the effect of duration (M1, M2, M3, M4) on $\dot{\mathrm{V}}_{2}, \dot{\mathrm{V}}_{\mathrm{E}}, \dot{\mathrm{V}}_{\mathrm{E}}: \dot{\mathrm{V}}_{2}, \mathrm{RER}$,

$215 \mathrm{OX}_{\mathrm{FAT}}, \mathrm{C}_{\mathrm{r}}, \mathrm{C}_{\mathrm{r}}^{\mathrm{J}}$ and \%HR $\mathrm{MAX}$; a two-way, RM ANOVA was used to assess the effect of duration,

216 category $\left(\mathrm{RPE}_{\mathrm{GEN}}, \mathrm{RPE}_{\mathrm{CON}}, \mathrm{RPE}_{\mathrm{KE}}\right)$ and the interaction (duration $\times$ category) on $\mathrm{RPE}$; and a three-

217 way, RM ANOVA was used to assess the effect of duration, condition, tissue site (VL, Gn, PFC)

218 and the interactions on TSI. When ANOVAs indicated a significant difference, Fisher's LSD post-

219 hoc test was used to conduct pairwise comparisons. The magnitude of changes was evaluated using

220 partial eta-squared $\left(\eta_{p}^{2}\right)$ interpreted according to Cohen's scale (small effect: $0.01<\eta_{p}^{2}<0.06$;

221 moderate effect: $0.06<\eta_{p}^{2}<0.14$; large effect: $\left.\eta_{p}^{2}>0.14\right)$. Statistical analyses were performed

222 using Statistica (version 13, StatSoft, Inc., Tulsa, OK, USA), and the level of significance was set

223 at $\mathrm{p}<0.05$.

\section{Results}

225 Paragraph \#15. All participants completed the 6TR, running a total distance of $58.3 \pm 10.5 \mathrm{~km}$

226 (average speed: $9.7 \pm 1.8 \mathrm{~km} \cdot \mathrm{h}^{-1}$ ) at an average $\% \mathrm{HR}_{\mathrm{MAX}}$ of $79.2 \pm 5.8 \%$ (HR: $139 \pm 6 \mathrm{bpm}$ ). Body

227 mass decreased $2.4 \pm 0.1 \mathrm{~kg}$ following the $6 \mathrm{TR}(3.4 \pm 1.8 \%$ of body weight). During each period

228 of SP running, speed decreased and PCI increased significantly with large effect sizes, and $229 \% \mathrm{HR}_{\mathrm{MAX}}$ did not change significantly (Table 1). There were significant and large increases in RPE 230 as a function of duration $\left(\mathrm{p}<0.001, \eta_{p}^{2}=0.505\right)$, with no significant effects of category $(\mathrm{p}=0.931$, $\left.231 \eta_{p}^{2}=0.010\right)$ or any interaction $\left(\mathrm{p}=0.559, \eta_{p}^{2}=0.111\right)$ (Figure 2$)$.

234 Paragraph \#16. The speeds used in each module were constant, by design, across modules in 10$\mathrm{CR}$, and were not significantly different across modules in HILL (M1: $8.79 \pm 1.01 \mathrm{~km} \cdot \mathrm{h}^{-1}$, M2: $\left.8.43 \pm 1.47 \mathrm{~km} \cdot \mathrm{h}^{-1}, \mathrm{M} 3: 8.13 \pm 1.71 \mathrm{~km} \cdot \mathrm{h}^{-1}, \mathrm{M} 4: 8.13 \pm 1.71 \mathrm{~km} \cdot \mathrm{h}^{-1} ; \mathrm{p}=0.083, \eta_{p}^{2}=0.267\right)$. In the $10-\mathrm{CR}$ condition, there were significant and large increases in $\% \mathrm{HR}_{\mathrm{MAX}}, \dot{\mathrm{V}} \mathrm{O}_{2}, \mathrm{OX}_{\mathrm{FAT}}$ and $\mathrm{C}_{\mathrm{r}}$, 
238 significant and large decreases in RER, and no significant changes in $\dot{\mathrm{V}}_{\mathrm{E}}, \mathrm{C}_{\mathrm{r}}^{\mathrm{J}}$, and $\dot{\mathrm{V}}_{\mathrm{E}}: \dot{\mathrm{V}}_{2}(\mathrm{Table}$

239 2). In the HILL condition, there were significant and large decreases in RER, significant and large 240 increases in $\mathrm{OX}_{\mathrm{FAT}}$, and no significant changes in $\dot{\mathrm{V}} \mathrm{O}_{2}, \dot{\mathrm{V}}_{\mathrm{E}}, \dot{\mathrm{V}}_{\mathrm{E}}: \dot{\mathrm{V}} \mathrm{O}_{2}, \% \mathrm{HR}_{\mathrm{MAX}}, \mathrm{C}_{\mathrm{r}}$ and $\mathrm{C}_{\mathrm{r}} \mathrm{J}$ (Table $2413)$.

242 Paragraph \#17. For TSI, there was a significant and large effect for site $\left(\mathrm{p}=0.001, \eta^{2} p=0.611\right)$, 243 but there were no significant effects of duration $\left(\mathrm{p}=0.515, \eta_{p}^{2}=0.101\right)$, condition $\left(\mathrm{p}=0.091, \eta^{2}{ }_{p}\right.$ $244=0.354$ ), or any interactions (Figure 3). Post-hoc testing indicated that TSI in PFC was 245 significantly greater than VL $(\mathrm{p}=0.001)$ and $\mathrm{Gn}(\mathrm{p}=0.001)$, and VL and Gn were not statistically 246 different from each other $(p=0.915)$. For the RPE variables during the HILL condition, there were 247 no significant effects of duration $\left(\mathrm{p}=0.164, \eta_{p}^{2}=0.212\right)$, category $\left(\mathrm{p}=0.906, \eta_{p}^{2}=0.014\right)$ or any 248 interactions $\left(\mathrm{p}=0.986, \eta_{p}^{2}=0.023\right)$ (Figure 2).

*** insert Table 2 about here ***

250

*** insert Table 3 about here ***

251

*** insert Figure 3 about here ***

\section{Discussion}

253 Paragraph \#18. The aim of this study was to investigate the effect of exercise duration on 254 cardiorespiratory responses $\left(\dot{\mathrm{V}}_{2}, \dot{\mathrm{V}}_{\mathrm{E}}, \dot{\mathrm{V}}_{\mathrm{E}}: \dot{\mathrm{V}}_{2}\right.$, RER, \%HR $\left.\mathrm{MAX}\right)$, energy cost of running $\left(\mathrm{C}_{\mathrm{r}}\right.$ and 255 $\mathrm{C}_{\mathrm{r}}^{\mathrm{J}}$ ), muscle tissue and cerebral oxygenation (TSI), and differentiated perceived exertion (RPE), at 256 moderate and heavy exercise intensities within a 6 hour treadmill run. Participants completed an average of $58.3 \mathrm{~km}$, and there was a progressive decrease in running speed throughout the 6TR (positive pacing) with increases in PCI (cardiac drift) and RPE as a function of duration during the self-paced periods of running. During 10-CR, RER and running economy decreased, and $\% \mathrm{HR}_{\mathrm{MAX}}, \mathrm{OX}_{\mathrm{FAT}}$ and $\mathrm{C}_{\mathrm{r}}$ increased. During HILL, RER decreased, and $\mathrm{OX}_{\mathrm{FAT}}$ increased.

261 Paragraph \#19. The 10-CR components of the modules were performed on level gradient $(0 \%)$ 262 and at a speed comparable to the average speed of the 6TR. As expected, exercise intensity during 263 $10-\mathrm{CR}$ was moderate $\left(53.9-56.4 \%\right.$ of $\left.\dot{\mathrm{VO}}_{2 \mathrm{MAX}}\right)$. We measured increases in cardiorespiratory 
264 parameters $\% \mathrm{HR}_{\mathrm{MAX}}$ and $\dot{\mathrm{V}} \mathrm{O}_{2}$, as well as changes in substrate utilization as estimated from changes 265 in $\mathrm{OX}_{\mathrm{FAT}}$ and RER. These results were expected, as previous studies conducted following events 266 ranging $10-149 \mathrm{~km}$, performed at intensities ranging $39-85 \%$ of $\dot{\mathrm{V}} \mathrm{O}_{2 \mathrm{MAX}}$ (including self-paced 267 events), have consistently reported increases in $\dot{V}_{2}$ (Gimenez et al. 2013; Hausswirth et al. 1996; 268 Hunter \& Smith 2007; Kyröläinen et al. 2000; Nicol et al. 1991; Xu \& Montgomery 1995) and 269 decreases in RER (Gimenez et al. 2013; Millet et al. 2000; Vernillo et al. 2016b; Vernillo et al. 270 2015). In the current study, the increased $C_{r}$ without changes in $C_{r}^{J}$ are likely explained by changes 271 in substrate utilization based on in $\mathrm{OX}_{\mathrm{FAT}}$ and RER. These results extends findings of increased $\mathrm{C}_{\mathrm{r}}$ 272 after a marathon (Brueckner et al. 1991; Hausswirth et al. 1996; Hunter \& Smith 2007; Kyröläinen 273 et al. 2000; Nicol et al. 1991; Xu \& Montgomery 1995), as well as the absence of changes in $\mathrm{C}_{\mathrm{r}}^{\mathrm{J}}$ 274 after a 65-km mountain ultramarathon (Vernillo et al. 2015). As such, the different outcomes in 275 studies reporting changes in the energy cost of running could have originated from the use of 276 different methods of calculation $\left(\mathrm{C}_{\mathrm{r}}\right.$ and $\left.\mathrm{C}_{\mathrm{r}}^{\mathrm{J}}\right)$.

277 Paragraph \#20. The HILL components of the modules were performed on an uphill gradient $278(10 \%)$ and at a heavy exercise intensity $\left(71.9-79.7 \%\right.$ of $\left.\dot{\mathrm{V}} \mathrm{O}_{2 \mathrm{MAX}}\right)$. During HILL, we measured only 279 changes in substrate utilization, with decreased RER and increased $\mathrm{OX}_{\mathrm{FAT}}$, with non-significant 280 decreases in $\dot{\mathrm{V}} \mathrm{O}_{2}$. These results were not expected, but indicate that the ability to exercise at a 281 heavy intensity (Gaesser \& Poole 1996) may not be altered within the 6TR. Additionally, the 282 absence of change in $\dot{\mathrm{V}}_{\mathrm{E}}$ and $\dot{\mathrm{V}}_{\mathrm{E}}: \dot{\mathrm{V}}_{2}$ at moderate and heavy exercise intensities contrasts with 283 other studies following trail ultramarathons (Millet et al. 2000; Vernillo et al. 2014), and indicates 284 that prolonged running with bouts of heavy intensity, but no downhill component, has small effects 285 on the cardiorespiratory response of trained ultramarathon runners. The absence of change in $C_{r}{ }^{J}$ 286 in our study is also in agreement with results of a study following a 65-km mountain ultramarathon 287 performed on trails (Vernillo et al. 2015), but differs from other studies having measured improved 288 (decreased) cost of running and walking following longer $(330 \mathrm{~km})$ mountain ultramarathons 289 (Vernillo et al. 2016a; Vernillo et al. 2014). However, in the current study the uphill gradient 290 condition was chosen to increase exercise intensity while minimizing the contribution of elastic 291 energy in gait, in order to control the possibility raised by other authors that changes in 292 microvascular structure could have increased muscle tissue energy requirements (Vernillo et al. 293 2016a). Another perspective to explain the absence of change in $C_{r}^{J}$ may reside in the specific 
294 muscular adaptations derived from the typical high mileage training performed by ultramarathon 295 runners. Unfortunately, we could not test this hypothesis, as we did not collect specific training 296 background variables in the current study participants. Nonetheless, the results of 10-CR and HILL 297 indicate that the effects of prolonged running with no downhill gradient were associated with 298 changes in substrate utilization, increased cardiorespiratory parameters and Cr only at the moderate 299 intensity, and with unchanged $\dot{\mathrm{V}}_{\mathrm{E}}$ and $\dot{\mathrm{V}}_{\mathrm{E}}: \dot{\mathrm{V}}_{2}$.

300 Paragraph \#21. Therefore, another major finding of the current study is the absence of change of 301 tissue oxygenation in two muscle and one cerebral sites as a function of exercise duration, across either the 10-CR and HILL components of the modules. We report differences across sites, where TSI in PFC was higher than both VL and Gn. Despite the expected and marked differences in exercise intensity, TSI also did not decrease significantly between the 10-CR and HILL conditions. Although one previous study observed tissue oxygenation alterations following prolonged duration running (Vernillo et al. 2016a), it is possible that the important downhill running component could have contributed to impair tissue structure and microcirculatory function, leading to altered tissue oxygenation (Vernillo et al. 2016a). In the current study, we sought to minimize the potentially confounding effects of the mode of muscle contraction (such as elicited by repeated downhill running). Further, as in the current study, differences in site, but no effect of exercise duration, were reported for muscle and cerebral oxygenation during a $4 \mathrm{~h}$ cycling exercise (Rupp et al. 2013). However, alterations in oxygen-dependent metabolic processes attributed to decreased mitochondrial efficiency, determined using biopsies of the VL muscle, were measured after a 24 $\mathrm{h}$ simulated adventure race (running, kayaking, cycling) at $\sim 60 \%$ of $\dot{\mathrm{V}} \mathrm{O}_{2 \mathrm{MAX}}$ (Fernström et al. 2007). As such, it is possible that the exercise duration was too short in the current study to elicit metabolic changes at tissue level. Therefore, the results of the current study indicate that tissue oxygenation in the microvasculature of two muscles and one cerebral sites was not impaired by exercise duration at moderate and heavy exercise intensities.

Paragraph \#22. Finally, we report an increase in RPE in three categories used in this study as a function of duration across SP, but the categories of RPE were not different to each other. The absence of differences between RPE categories, and the relatively low group mean values are similar to those reported during other prolonged running events (Kerhervé et al. 2015; Vercruyssen et al. 2012). Therefore, despite increased RPE values as a function of duration, the absence of 
324 differences across RPE categories indicate that differentiated RPE scales potentially do not provide

325 a useful measure to differentiate the specific categories used in the current study for prolonged 326 duration exercise. Consequently, we can hypothesize that RPE is a general indicator of psycho-

327 physiological load, influenced by fatigue (Marcora et al. 2008), but independent from sensory 328 afferents (Marcora 2009). Trained endurance athletes could also readily use, knowingly or not, 329 specific strategies to limit or reduce RPE during fatiguing endurance exercise, such as self-talk 330 (Blanchfield et al. 2014). Therefore, additional research is required to investigate the etiology of 331 psycho-physiological fatigue, including the role of attentional focus, cognitive control and metacognition in relation to indicators of metabolic load and efficiency. Combined, the findings

333

334

335

336

337

338

339

340

341

342

343

344

345

346

347

348

349

350

351

352

353

354 of the current study indicate that at moderate intensity, increased exercise duration was associated with increased cardiorespiratory load, increased energy cost of running only when expressed as oxygen consumption per unit distance, changes in substrate utilization, and increased perceived exertion. During periods of heavy exercise intensity, increased exercise duration was associated with changes in substrate utilization but not cardiorespiratory load. Overall, exercise duration was not associated with changes in ventilatory efficiency, energy cost of running expressed as energy expenditure per unit distance, or tissue oxygenation, regardless of exercise intensity.

Paragraph \#23. There were three main limitations to this study. First, we could not perform continuous measurements of TSI because the devices could not remain in contact with the skin for extended periods without causing discomfort and additional sweating, the latter being incompatible with consistent measurements. Two trained investigators were present to fix and remove the devices from the testing sites at each module to reduce the total time stopped (18 \pm 1 min), and we minimized the effect of the time stopped by adding periods of self-paced running before and after the 10-CR and HILL conditions. There were also non-significant changes in speed in the HILL condition, which could have minimized expected increases in metabolic load. However, we permitted to vary speed in this condition to ensure the completion of the 6TR, and we aimed to establish whether exercise performed at heavy intensity would alter cardiorespiratory efficiency, energy cost of running and tissue oxygenation compared to self-paced running. Second, we did not record weekly mileage or lifetime training experience, which could constitute important explanatory factors for the variables collected. Third, we did not record nutrition or hydration intake, although these could have important implications for the results of the current study. This constitutes an important direction for future studies. 


\section{Conclusions}

356 Paragraph \#24. Speed decreased overall, and heart rate (cardiac drift) and the subjective

357 perception of effort increased, during a $6 \mathrm{~h}$ treadmill run. Running at $\sim 54-56 \% \dot{\mathrm{V}} \mathrm{O}_{2 \mathrm{MAX}}$ on level 358 ground was associated with increases in systemic oxygen consumption, heart rate and decreases 359 in RER, and running at $\sim 72-82 \% \dot{\mathrm{VO}}_{2 \mathrm{MAX}}$ was associated only with decreases in RER. There were 360 no changes in ventilatory efficiency, energy cost of running, and muscular and cerebral tissue 361 oxygenation as a function of exercise duration, at moderate and heavy exercise intensity. 362 Therefore, the major changes observed within a $6 \mathrm{~h}$ treadmill run with no downhill component 363 were a modification of substrate utilization and increased heart rate, but exercise capacity remained 364 unchanged at moderate and heavy exercise intensities. We recommend future research to be 365 directed to establishing the potential links between the dynamics of energy cost of running and 366 nutrition and hydration status, as well as training status and lifetime training experience. 


\section{Acknowledgements}

368 The authors would like to thank all the participants for their effort and valuable time, the

369 university's laboratory technicians (Stephen Bishop, Alysha Hyde, Darren Morrow and Ava

370 Kerr) for their technical support, and Ms. Benjie Bartos for editing and correcting the

371 manuscript.

372 


\section{Figure legends}

374 Figure 1. Six Hour Treadmill Run Protocol. Schematic representation of the timing of exercise 375 and measurements performed during the $6 \mathrm{~h}$ treadmill run (6TR).

376 Figure 2. Ratings of Perceived Exertion. Ratings of perceived exertion (RPE) measured using

377 the 6-20 Borg scale during the self-paced periods of running (panel A), and during the HILL 378 condition during the modules (Panel B). * = significant main effect of exercise duration $; \mathrm{p}<0.05$.

379 Figure 3. Tissue Saturation Index. Tissue saturation index (TSI) measured with near-infrared 380 spectroscopy at the prefrontal cortex (Panel A), vastus lateralis muscle (Panel B) and 381 gastrocnemius muscle (Panel C). \# = significant main effect of tissue site $; \mathrm{p}<0.05$. 


\section{References}

384

385

386

387

388

389

390

391

392

393

394

395

396

397

398

399

400

401

402

403

404

405

406

407

408

409

410

411

412

413

414

415

416

417

418
Blanchfield AW, Hardy J, De Morree HM, Staiano W, and Marcora SM. 2014. Talking yourself out of exhaustion: the effects of self-talk on endurance performance. Medicine and Science in Sports and Exercise 46:998-1007. 10.1249/MSS.0000000000000184

Brueckner JC, Atchou G, Capelli C, Duvallet A, Barrault D, Jousselin E, Rieu M, and di Prampero PE. 1991. The energy cost of running increases with the distance covered. European Journal of Applied Physiology 62:385-389. 10.1007/BF00626607

deMorree HM, Klein C, and Marcora SM. 2012. Perception of effort reflects central motor command during movement execution. Psychophysiology 49:1242-1253. 10.1111/j.14698986.2012.01399.x

di Prampero PE, Atchou G, Bruckner J-C, and Moia C. 1986. The energetics of endurance running. European Journal of Applied Physiology 55:259-266.

Duncan A, Meek JH, Clemence M, Elwell CE, Fallon P, Tyszczuk L, Cope M, and Delpy DT. 1996. Measurement of cranial optical path length as a function of age using phase resolved Near Infrared Spectroscopy. Pediatric Research 39:889-894. 10.1203/00006450199605000-00025

Fernström M, Bakkman L, Tonkonogi M, Shabalina IG, Rozhdestvenskaya Z, Mattsson CM, Enqvist JK, Ekblom B, and Sahlin K. 2007. Reduced efficiency, but increased fat oxidation, in mitochondria from human skeletal muscle after 24-h ultraendurance exercise. Journal of Applied Physiology 102:1844-1849. 10.1152/japplphysiol.01173.2006

Frayn KN. 1983. Calculation of substrate oxidation rates in vivo from gaseous exchange. Journal of Applied Physiology 55:628-634.

Gaesser GA, and Poole DC. 1996. The slow component of oxygen uptake kinetics in humans. Exercise and Sports Science Reviews 24:35-70.

Gimenez P, Kerhervé H, Messonnier LA, Féasson L, and Millet GY. 2013. Changes in the energy cost of running during a 24-h treadmill exercise. Medicine and Science in Sports and Exercise 45:1807-1813. 10.1249/MSS.0b013e318292c0ec

Hampson DB, St Clair Gibson A, Lambert MI, and Noakes TD. 2001. The influence of sensory cues on the perception of exertion during exercise and central regulation of exercise performance. Sports Medicine 31:935-952. 10.2165/00007256-200131130-00004

Hausswirth C, Bigard AX, Berthelot M, Thomaidis M, and Guezennec CY. 1996. Variability in energy cost of running at the end of a triathlon and a marathon. International Journal of Sports Medicine 17:572-579. 10.1055/s-2007-972897

Hunter I, and Smith GA. 2007. Preferred and optimal stride frequency, stiffness and economy: changes with fatigue during a 1-h high-intensity run. European Journal of Applied Physiology 100:653-651. 10.1007/s00421-007-0456-1 
419 Kerhervé HA, Millet GY, and Solomon C. 2015. The dynamics of speed selection and psycho420 physiological load during a mountain ultramarathon. PLoS One 10:e0145482.

421

422

423

424

425

426

427

428

429

430

431

432

433

434

435

436

437

438

439

440

441

442

443

444

445

446

447

448

449

450

451

452

453

454 10.1371/journal.pone.0145482

Kyröläinen H, Pullinen T, Candau R, Avela J, Huttunen P, and Komi PV. 2000. Effects of marathon running on running economy and kinematics. European Journal of Applied Physiology 82:297-304. 10.1007/s004210000219

Lazzer S, Salvadego D, Rejc E, Buglione A, Antonutto G, and di Prampero PE. 2012. The energetics of ultra-endurance running. European Journal of Applied Physiology 112:17091715. 10.1007/s00421-011-2120-z

Marcora SM. 2009. Perception of effort during exercise is independent of afferent feedback from skeletal muscles, heart, and lungs. Journal of Applied Physiology 106:2060-2062. 10.1152/japplphysiol.90378.2008

Marcora SM, Bosio A, and de Moree HM. 2008. Locomotor muscle fatigue increases cardiorespiratory responses and reduces performance during intense cycling exercise independently from metabolic stress American Journal of Physiololgy 294:R874-R883. 10. 1152/ajpregu.00678.2007

Mihevic P. 1981. Sensory cues for perceived exertion. Medicine and Science in Sports and Exercise 13:150-153.

Millet GY, Lepers R, Lattier G, Martin V, Babault N, and Maffiuletti N. 2000. Influence of longterm fatigue on the oxygen cost of two types of locomotion. European Journal of Applied Physiology 83:376-380.

Minetti AE, Ardigo LP, and Saibene F. 1994. Mechanical determinants of the minimum energy cost of gradient running in humans. Journal of Experimental Biology 195:211-225.

Nicol C, Komi P, and Marconnet P. 1991. Effects of marathon fatigue on running kinematics and economy. Scandinavian Journal of Medicine \& Science in Sports 1:195-204. 10.1111/j.1600-0838.1991.tb00296.x

Nicolò A, Marcora SM, and Sacchetti M. 2015. Respiratory frequency is strongly associated with perceived exertion during time trials of different duration. Journal of Sports Sciences 34:1199-1206. 10.1080/02640414.2015.1102315

Robertson CV, and Marino FE. 2016. Viewpoint: A role for the prefrontal cortex in exercise tolerance and termination. Journal of Applied Physiology 120:464-466. 10.1152/japplphysiol.00363.2015

Rupp T, Jubeau M, Millet GY, Wuyam B, Levy P, Verges S, and Perrey S. 2013. Muscle, prefrontal, and motor cortex oxygenation profiles during prolonged fatiguing exercise. Advances in Experimental Medicine and Biology 789:149-155. 10.1007/978-1-4614-7411$1 \_21$ 
455

456

457

458

459

460

461

462

463

464

465

466

467

468

469

470

471

472

473

474

475

476

477

478

479

480

481

482

483

484

485

486

487

488

489

490

491
Sear JA, Hoare TK, Scanlan AT, Abt GA, and Dascombe B. 2010. The effects of whole-body compression garments on prolonged high-intensity intermittent exercise. Journal of Strength and Conditioning Research 24:1901-1910. doi: 10.1519/JSC.0b013e3181db251b

Tucker R, and Noakes TD. 2009. The anticipatory regulation of performance: The physiological basis for pacing strategies and the development of a perception-based model for exercise performance. British Journal of Sport Medicine 43:392-400. 10.1136/bjsm.2008.050799

van Beekvelt MCP, Borghuis MS, Van Engelen BGM, Wevers RA, and Colier WN. 2001. Adipose tissue thickness affects in vivo quantitative near-IR spectroscopy in human skeletal muscle. Clinical Science (London) 101:21-28.

Vercruyssen F, Easthope C, Bernard T, Hausswirth C, Bieuzen F, Gruet M, and Brisswalter J. 2012. The influence of wearing compression stockings on performance indicators and physiological responses following a prolonged trail running exercise. European Journal of Sport Science 14:144-150. 10.1080/17461391.2012.730062

Vernillo G, Brighenti A, Limonta E, Trabucchi P, Malatesta D, Millet GP, and Schena F. 2016a. Effects of ultratrail running on skeletal muscle oxygenation dynamics. International Journal of Sports Physiology and Performance [Epub ahead of print]:1-25. 10.1123/ijspp.2015-0745

Vernillo G, Savoldelli A, Skafidas S, Zignoli A, La Torre A, Pellegrini B, Giardini G, Trabucchi P, Millet GP, and Schena F. 2016b. An extreme mountain ultra-marathon decreases the cost of uphill walking and running. Frontiers in Physiology 7:530. 10.3389/fphys.2016.00530

Vernillo G, Savoldelli A, Zignoli A, Skafidas S, Fornasiero A, Torre AL, Bortolan L, Pellegrini B, and Schena F. 2015. Energy cost and kinematics of level, uphill and downhill running: fatigue-induced changes after a mountain ultramarathon. Journal of Sports Sciences 33:1998-2005. 10.1080/02640414.2015.1022870

Vernillo G, Savoldelli A, Zignoli A, Trabucchi P, Pellegrini B, Millet GP, and Schena F. 2014. Influence of the world's most challenging mountain ultra-marathon on energy cost and running mechanics. European Journal of Applied Physiology 114:929-939. 10.1007/s00421-014-2824-y

Wollseiffen P, Schneider S, Martin L, Kerhervé HA, Klein T, and Solomon C. 2016. The effect of $6 \mathrm{~h}$ of running on brain activity, mood, and cognitive performance. Experimental Brain Research 234:1829-1836. 10.1007/s00221-016-4587-7

$\mathrm{Xu} \mathrm{F}$, and Montgomery DL. 1995. Effect of prolonged exercise at 65 and $80 \%$ of VO2max on running economy. International Journal of Sports Medicine 16:309-313. 10.1055/s-2007973011 
Table $\mathbf{1}$ (on next page)

Speed, heart rate (HR) and physiological cost index (PCI) during the three self-paced periods (SP1, SP2, SP3). 
1 Table 1. Speed, heart rate relative to individual maximum $\left(\% \mathrm{HR}_{\mathrm{MAX}}\right)$ and physiological cost index 2 (PCI) during the three self-paced periods (SP1, SP2, SP3).

\begin{tabular}{|c|c|c|c|c|c|c|}
\hline & & Mean \pm SD & $95 \%$ CI & $\%$ change & p & $\eta_{p}^{2}$ \\
\hline \multirow{3}{*}{ Speed $\left(\mathrm{km} \cdot \mathrm{h}^{-1}\right)$} & SP1 & $10.3 \pm 1.86$ & $8.70 \pm 11.8$ & & \multirow{3}{*}{$0.038^{*}$} & \multirow{3}{*}{$0.473^{\mathrm{L}}$} \\
\hline & SP2 & $9.87 \pm 1.96$ & $8.24 \pm 11.5$ & -4.0 & & \\
\hline & SP3 & $9.13 \pm 2.07$ & $7.40 \pm 10.9$ & -11.1 & & \\
\hline \multirow{3}{*}{$\% \mathrm{HR}_{\mathrm{MAX}}(\%)$} & SP1 & $78.5 \pm 6.96$ & $72.7 \pm 84.3$ & & \multirow{3}{*}{0.228} & \multirow{3}{*}{$0.199^{\mathrm{L}}$} \\
\hline & SP2 & $81.1 \pm 6.52$ & $75.7 \pm 86.6$ & 3.4 & & \\
\hline & SP3 & $79.7 \pm 6.22$ & $74.5 \pm 84.9$ & 1.8 & & \\
\hline \multirow{3}{*}{$\mathrm{PCI}\left(\mathrm{bpm} \cdot \mathrm{m}^{-1}\right)$} & SP1 & $0.83 \pm 0.19$ & $0.68 \pm 0.99$ & & \multirow{3}{*}{$0.009 *$} & \multirow{3}{*}{$0.608^{L}$} \\
\hline & SP2 & $0.90 \pm 0.23$ & $0.71 \pm 1.09$ & 7.8 & & \\
\hline & $\mathrm{SP} 3$ & $0.97 \pm 0.27$ & $0.74 \pm 1.19$ & 15.6 & & \\
\hline
\end{tabular}

3 Data are group mean \pm SD.

4 Symbols used: * (significant main effect of duration, at $\mathrm{p}<0.05$ ), ${ }^{\mathrm{L}}$ (large effect). 


\section{Table 2 (on next page)}

Changes in the cardiorespiratory variables and energy cost, measured during the 10-CR condition of the modules. 
1 Table 2. Changes in the cardiorespiratory variables and energy cost, measured during the 10-CR 2 condition of the modules.

\begin{tabular}{|c|c|c|c|c|c|c|}
\hline & Module & Mean \pm SD & $95 \%$ CI & $\%$ change & p & $\eta_{p}^{2}$ \\
\hline & 1 & $32.1 \pm 3.3$ & $29.4 \pm 34.9$ & & \multirow{4}{*}{$0.020^{*}$} & \multirow{4}{*}{$0.367^{\mathrm{L}}$} \\
\hline$\dot{\mathrm{V}} \mathrm{O}_{2}$ & 2 & $31.2 \pm 2.6$ & $29.0 \pm 33.4$ & -2.6 & & \\
\hline \multirow[t]{2}{*}{$\left(\mathrm{mL} \cdot \mathrm{kg}^{-1} \cdot \mathrm{min}^{-1}\right)$} & 3 & $32.7 \pm 3.1$ & $30.2 \pm 35.3$ & +2.2 & & \\
\hline & 4 & $33.3 \pm 3.3$ & $30.5 \pm 36.0$ & +3.6 & & \\
\hline & 1 & $49.2 \pm 6.47$ & $43.8 \pm 54.6$ & & \multirow{4}{*}{0.061} & \multirow{4}{*}{$0.290^{\mathrm{L}}$} \\
\hline$\dot{\mathrm{V}}_{\mathrm{E}}$ & 2 & $50.0 \pm 6.45$ & $44.6 \pm 55.4$ & +2.0 & & \\
\hline \multirow[t]{2}{*}{$\left(\mathrm{L} \cdot \mathrm{min}^{-1}\right)$} & 3 & $52.6 \pm 7.63$ & $46.3 \pm 59.0$ & +7.1 & & \\
\hline & 4 & $53.8 \pm 6.17$ & $48.6 \pm 58.9$ & +10.0 & & \\
\hline \multirow{4}{*}{$\dot{\mathrm{V}}_{\mathrm{E}}: \dot{\mathrm{V}} \mathrm{O}_{2}$} & 1 & $25.8 \pm 1.5$ & $24.5 \pm 27.0$ & & & \multirow{4}{*}{$0.187^{\mathrm{L}}$} \\
\hline & 2 & $27.0 \pm 3.0$ & $24.6 \pm 29.5$ & +5.0 & \multirow{3}{*}{0.218} & \\
\hline & 3 & $27.1 \pm 3.3$ & $24.3 \pm 29.8$ & +4.9 & & \\
\hline & 4 & $27.5 \pm 3.1$ & $24.9 \pm 30.0$ & +6.6 & & \\
\hline \multirow{4}{*}{ RER } & 1 & $0.92 \pm 0.06$ & $0.87 \pm 0.98$ & & \multirow{4}{*}{$0.023 *$} & \multirow{4}{*}{$0.359^{\mathrm{L}}$} \\
\hline & 2 & $0.89 \pm 0.05$ & $0.85 \pm 0.93$ & -3.8 & & \\
\hline & 3 & $0.87 \pm 0.04$ & $0.84 \pm 0.90$ & -5.7 & & \\
\hline & 4 & $0.86 \pm 0.03$ & $0.84 \pm 0.89$ & -6.3 & & \\
\hline \multirow{4}{*}{$\begin{array}{l}\mathrm{OX}_{\mathrm{FAT}} \\
\left(\mathrm{g} \cdot \mathrm{min}^{-1}\right)\end{array}$} & 1 & $0.29 \pm 0.23$ & $0.13 \pm 0.45$ & & \multirow{4}{*}{$0.030^{*}$} & \multirow{4}{*}{$0.342^{\mathrm{L}}$} \\
\hline & 2 & $0.41 \pm 0.16$ & $0.30 \pm 0.52$ & +71 & & \\
\hline & 3 & $0.50 \pm 0.12$ & $0.42 \pm 0.58$ & +106 & & \\
\hline & 4 & $0.52 \pm 0.14$ & $0.43 \pm 0.62$ & +114 & & \\
\hline \multirow{4}{*}{$\begin{array}{l}\mathrm{C}_{\mathrm{r}} \\
\left(\mathrm{mL} \cdot \mathrm{kg}^{-1} \cdot \mathrm{m}^{-1}\right)\end{array}$} & 1 & $0.172 \pm 0.020$ & $0.158 \pm 0.185$ & & \multirow{4}{*}{$0.004 *$} & \multirow{4}{*}{$0.464^{\mathrm{L}}$} \\
\hline & 2 & $0.166 \pm 0.016$ & $0.155 \pm 0.177$ & -3.4 & & \\
\hline & 3 & $0.175 \pm 0.019$ & $0.163 \pm 0.188$ & +2.1 & & \\
\hline & 4 & $0.179 \pm 0.020$ & $0.165 \pm 0.192$ & +3.8 & & \\
\hline \multirow{4}{*}{$\begin{array}{l}\mathrm{C}_{\mathrm{r}}^{\mathrm{J}} \\
\left(\mathrm{J} \cdot \mathrm{kg}^{-1} \cdot \mathrm{m}^{-1}\right)\end{array}$} & 1 & $3.56 \pm 0.40$ & $3.23 \pm 3.89$ & & \multirow{4}{*}{0.062} & \multirow{4}{*}{$0.289^{\mathrm{L}}$} \\
\hline & 2 & $3.41 \pm 0.34$ & $3.13 \pm 3.70$ & -3.7 & & \\
\hline & 3 & $3.59 \pm 0.40$ & $3.26 \pm 3.92$ & +1.1 & & \\
\hline & 4 & $3.64 \pm 0.40$ & $3.31 \pm 3.98$ & +2.6 & & \\
\hline & 1 & $82.5 \pm 8.3$ & $75.5 \pm 89.5$ & & \multirow{4}{*}{$0.001 *$} & \multirow{4}{*}{$0.817^{\mathrm{L}}$} \\
\hline & 2 & $86.4 \pm 8.1$ & $79.6 \pm 93.2$ & +4.8 & & \\
\hline & 3 & $88.6 \pm 7.3$ & $82.5 \pm 94.7$ & +7.6 & & \\
\hline & 4 & $89.5 \pm 6.7$ & $81.1 \pm 97.8$ & +13.6 & & \\
\hline
\end{tabular}

3 Data are group mean $\pm \mathrm{SD}$.

4 Symbols used: * (significant main effect of duration, at $\mathrm{p}<0.05$ ), ${ }^{\mathrm{L}}$ (large effect).

$5 \quad \dot{\mathrm{VO}}_{2}$ (Oxygen utilization), $\dot{\mathrm{V}}_{\mathrm{E}}$ (Minute ventilation), $\dot{\mathrm{V}}_{\mathrm{E}}: \dot{\mathrm{V}}_{2}$ (Ventilatory equivalent), RER

6 (Respiratory Exchange Ratio), $\mathrm{C}_{\mathrm{r}}$ and $\mathrm{C}_{\mathrm{r}}{ }^{\mathrm{J}}$ (Energy cost of running), $\% \mathrm{HR}_{\mathrm{MAX}}(\mathrm{Heart}$ rate relative to 7 individual maximum). 


\section{Table 3 (on next page)}

Changes in the cardiorespiratory variables and energy cost of running, measured during the HILL condition of the modules. 
1 Table 3. Changes in the cardiorespiratory variables and energy cost of running, measured during 2 the HILL condition of the modules.

\begin{tabular}{|c|c|c|c|c|c|c|}
\hline & Module & Mean \pm SD & $95 \%$ CI & $\%$ change & p-value & $\eta_{p}^{2}$ \\
\hline \multirow{4}{*}{$\begin{array}{l}\dot{\mathrm{V}} \mathrm{O}_{2} \\
\left(\mathrm{~mL} \cdot \mathrm{kg}^{-1} \cdot \mathrm{min}^{-1}\right)\end{array}$} & 1 & $47.4 \pm 6.7$ & $41.8 \pm 52.9$ & & \multirow{4}{*}{0.067} & \multirow{4}{*}{$0.283^{\mathrm{L}}$} \\
\hline & 2 & $43.9 \pm 9.8$ & $37.0 \pm 50.9$ & -7.5 & & \\
\hline & 3 & $42.9 \pm 9.8$ & $34.6 \pm 51.1$ & -9.9 & & \\
\hline & 4 & $42.5 \pm 11.5$ & $33.0 \pm 52.1$ & -10.9 & & \\
\hline \multirow{4}{*}{$\begin{array}{l}\dot{\mathrm{V}}_{\mathrm{E}} \\
\left(\mathrm{L} \cdot \mathrm{min}^{-1}\right)\end{array}$} & 1 & $80.1 \pm 14.2$ & $68.2 \pm 92.0$ & & \multirow{4}{*}{0.214} & \multirow{4}{*}{$0.188^{\mathrm{L}}$} \\
\hline & 2 & $73.3 \pm 14.9$ & $60.9 \pm 85.7$ & -8.0 & & \\
\hline & 3 & $73.4 \pm 14.1$ & $61.6 \pm 85.2$ & -7.6 & & \\
\hline & 4 & $73.0 \pm 17.7$ & $58.2 \pm 87.9$ & -8.1 & & \\
\hline \multirow{4}{*}{$\dot{\mathrm{V}}_{\mathrm{E}}: \dot{\mathrm{V}} \mathrm{O}_{2}$} & 1 & $24.0 \pm 2.0$ & $22.3 \pm 25.7$ & & \multirow{4}{*}{0.382} & \multirow{4}{*}{$0.133^{\mathrm{M}}$} \\
\hline & 2 & $23.9 \pm 2.6$ & $21.7 \pm 26.1$ & -0.4 & & \\
\hline & 3 & $24.9 \pm 3.3$ & $22.1 \pm 27.6$ & +3.4 & & \\
\hline & 4 & $24.8 \pm 2.0$ & $23.1 \pm 26.5$ & +3.7 & & \\
\hline \multirow{4}{*}{ RER } & 1 & $1.01 \pm 0.07$ & $0.95 \pm 1.06$ & & \multirow{4}{*}{$0.013^{*}$} & \multirow{4}{*}{$0.396^{\mathrm{L}}$} \\
\hline & 2 & $0.96 \pm 0.08$ & $0.89 \pm 1.02$ & -4.9 & & \\
\hline & 3 & $0.96 \pm 0.04$ & $0.92 \pm 0.99$ & -4.5 & & \\
\hline & 4 & $0.94 \pm 0.04$ & $0.91 \pm 0.98$ & -5.8 & & \\
\hline \multirow{4}{*}{$\begin{array}{l}\mathrm{OX}_{\mathrm{FAT}} \\
\left(\mathrm{g} \cdot \mathrm{min}^{-1}\right)\end{array}$} & 1 & $0.13 \pm 0.15$ & $0.03 \pm 0.24$ & & \multirow{4}{*}{$0.018^{*}$} & \multirow{4}{*}{$0.419^{\mathrm{L}}$} \\
\hline & 2 & $0.21 \pm 0.15$ & $0.10 \pm 0.32$ & +62 & & \\
\hline & 3 & $0.18 \pm 0.13$ & $0.08 \pm 0.27$ & +31 & & \\
\hline & 4 & $0.17 \pm 0.13$ & $0.07 \pm 0.26$ & +20 & & \\
\hline \multirow{4}{*}{$\begin{array}{l}\mathrm{C}_{\mathrm{r}} \\
\left(\mathrm{mL} \cdot \mathrm{kg}^{-1} \cdot \mathrm{m}^{-1}\right)\end{array}$} & 1 & $0.299 \pm 0.023$ & $0.283 \pm 0.315$ & & \multirow{4}{*}{0.403} & \multirow{4}{*}{$0.127^{\mathrm{L}}$} \\
\hline & 2 & $0.287 \pm 0.027$ & $0.268 \pm 0.306$ & -4.0 & & \\
\hline & 3 & $0.289 \pm 0.032$ & $0.267 \pm 0.311$ & -3.3 & & \\
\hline & 4 & $0.284 \pm 0.034$ & $0.260 \pm 0.308$ & -5.1 & & \\
\hline \multirow{4}{*}{$\begin{array}{l}\mathrm{C}_{\mathrm{r}}^{\mathrm{J}} \\
\left(\mathrm{J} \cdot \mathrm{kg}^{-1} \cdot \mathrm{m}^{-1}\right)\end{array}$} & 1 & $6.31 \pm 0.48$ & $5.90 \pm 6.71$ & & \multirow{4}{*}{0.206} & \multirow{4}{*}{$0.192^{\mathrm{L}}$} \\
\hline & 2 & $5.99 \pm 0.55$ & $5.54 \pm 6.45$ & -4.9 & & \\
\hline & 3 & $6.04 \pm 0.69$ & $5.47 \pm 6.62$ & -4.2 & & \\
\hline & 4 & $5.92 \pm 0.76$ & $5.29 \pm 6.55$ & -6.0 & & \\
\hline \multirow{4}{*}{$\begin{array}{l}\% \mathrm{HR}_{\mathrm{MAX}} \\
(\%)\end{array}$} & 1 & $97.8 \pm 5.96$ & $92.8 \pm 102.8$ & & \multirow{4}{*}{0.164} & \multirow{4}{*}{$0.337^{\mathrm{L}}$} \\
\hline & 2 & $98.8 \pm 3.88$ & $95.6 \pm 102.1$ & +1.2 & & \\
\hline & 3 & $99.2 \pm 3.74$ & $96.1 \pm 102.4$ & +1.8 & & \\
\hline & 4 & $100.4 \pm 3.82$ & $95.7 \pm 105.2$ & +3.3 & & \\
\hline
\end{tabular}

3

4 Symbols used: * (significant main effect of duration, at $\mathrm{p}<0.05$ ), ${ }^{\mathrm{M}}$ (moderate effect), ${ }^{\mathrm{L}}$ (large 5 effect).

$6 \quad \dot{\mathrm{V}} \mathrm{O}_{2}$ (Oxygen utilization), $\dot{\mathrm{V}}_{\mathrm{E}}$ (Minute ventilation), $\dot{\mathrm{V}}_{\mathrm{E}}: \dot{\mathrm{V}}_{2}$ (Ventilatory equivalent), RER

7 (Respiratory Exchange Ratio), $\mathrm{C}_{\mathrm{r}}$ and $\mathrm{C}_{\mathrm{r}}^{\mathrm{J}}$ (Energy cost of running), $\% \mathrm{HR}_{\mathrm{MAX}}$ (Heart rate relative to 8 individual maximum). 
Figure 1

Six hour treadmill run protocol.

Schematic representation of the timing of exercise and measurements performed during the $6 \mathrm{~h}$ treadmill run (6TR).

Continuous measures: Speed, Heart Rate

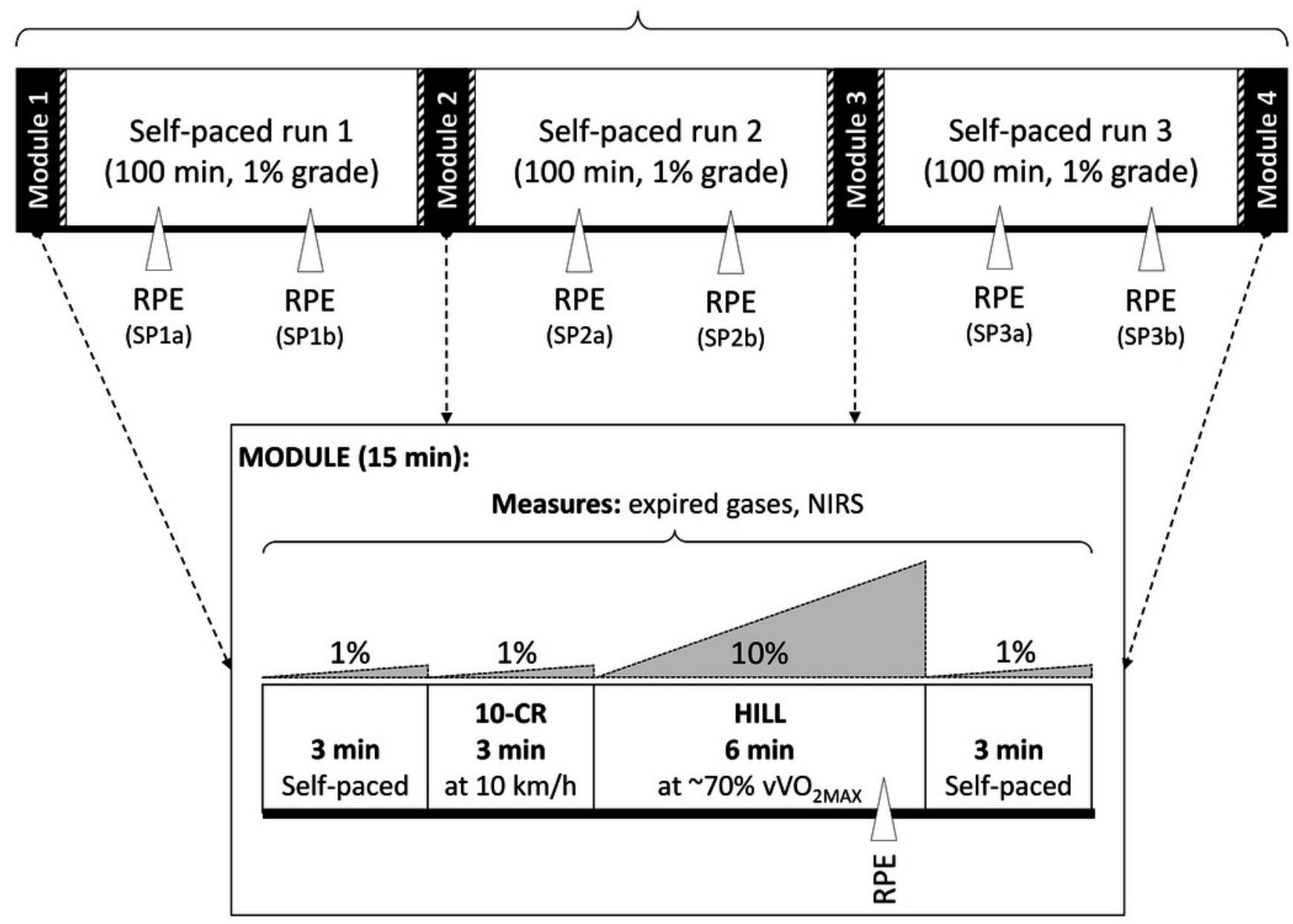


Figure 2

Ratings of perceived exertion.

Ratings of perceived exertion (RPE) measured using the 6-20 Borg scale during the self-paced periods of running (panel A), and during the HILL condition during the modules (Panel B).

$*=$ significant effect of exercise duration $; p<0.05$.

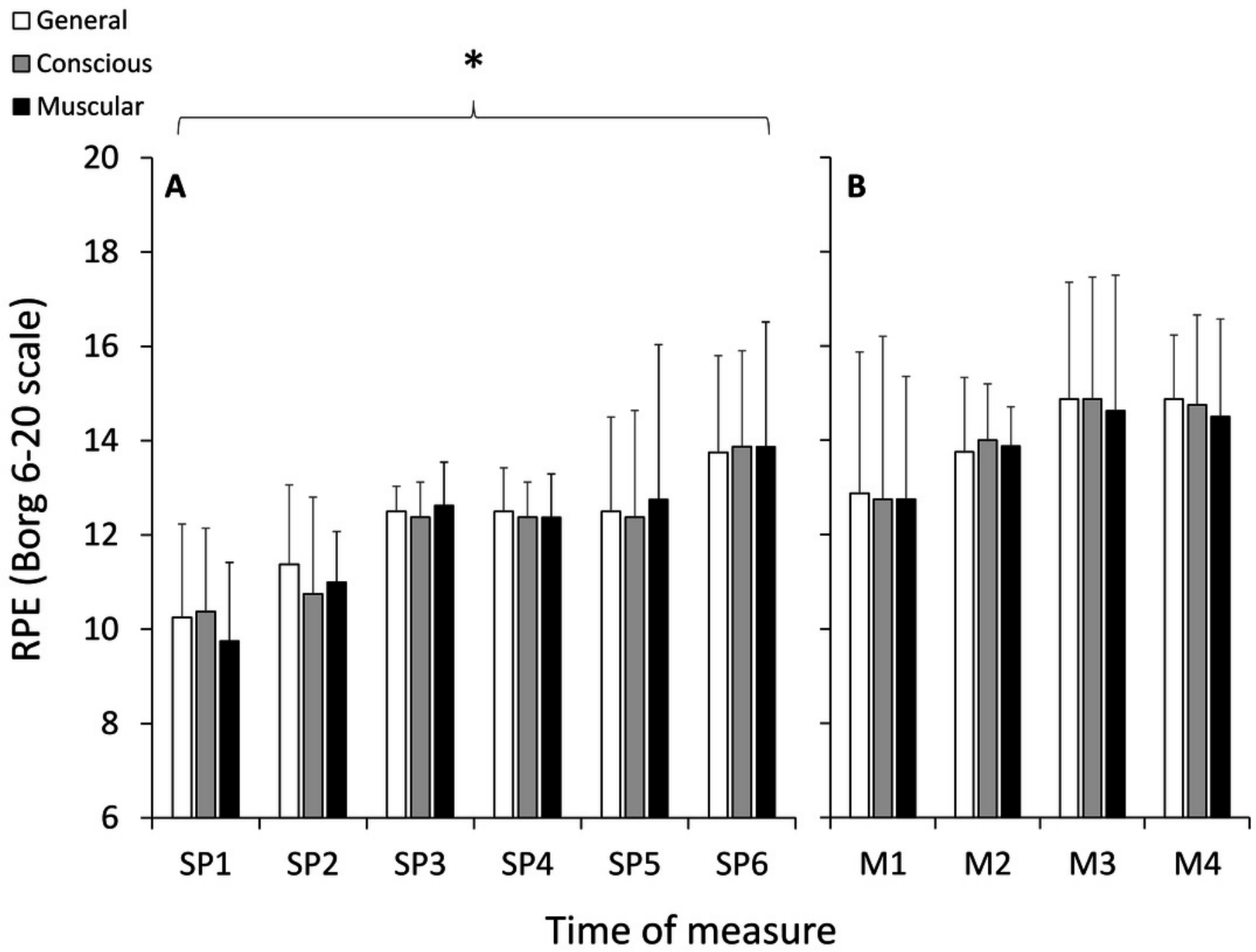


Figure 3

Tissue saturation index.

Tissue saturation index (TSI) measured with near-infrared spectroscopy at the vastus lateralis muscle (Panel A), gastrocnemius muscle (Panel B) and prefrontal cortex (Panel C).

$\#=$ significant effect of tissue site $; p<0.05$.

$\square$ Module 1

$\square$ Module 2

$\square$ Module 3

$\square$ Module 4
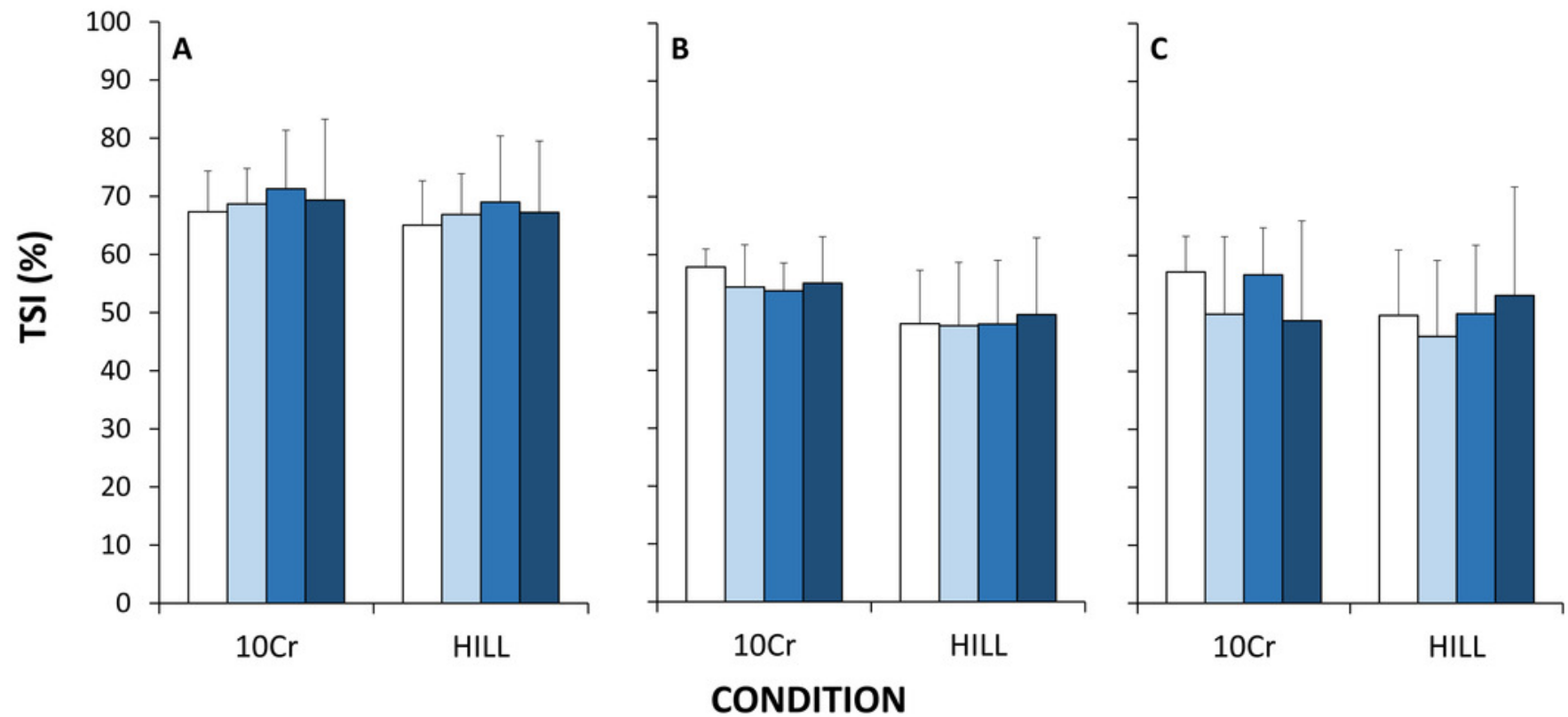